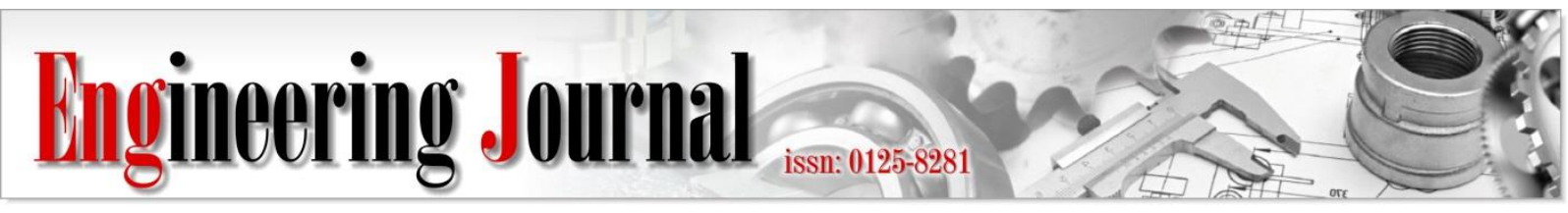

Article

\title{
Risk Factors Affecting Driver Severity of Single- Vehicle Run Off Road Crash for Thailand Highway
}

\author{
Chamroeun Se ${ }^{a}$, Thanapong Champahom ${ }^{b}$, Sajjakaj Jomnonkwao ${ }^{c}$, \\ and Vatanavongs Ratanavaraha ${ }^{\mathrm{d}, *}$
}

School of Transportation Engineering, Institute of Engineering, Suranaree University of Technology, 111 University Avenue, Suranaree Sub-district, Nakhon Ratchasima 30000, Thailand Email: ${ }^{a} c s e 027 @ g m a i l . c o m, ~ b d 5840564 @ g . s u t . a c . t h,{ }^{c}$ sajjakaj@gmail.com, ${ }^{d}$ vatanavongs@g.sut.ac.th (Corresponding author)

\begin{abstract}
Single-Vehicle Run Off Road (ROR) crash has been the leading crash type in terms of frequency and severity in Thailand. In this study, multinomial logit analysis was applied to identify the risk factors potentially influencing driver injury severity of singlevehicle ROR crash using accident records between 2011 and 2017 which were extracted from Highway Accident Information Management System (HAIMS) database. The analysis results show that the age of driver older than 55 years old, male driver, driver under influence of alcohol, drowsiness, ROR to left/right on straight roadway increase the probability of fatal crash, while other factors are found to mitigate severity such as the age of driver between 26-35 years old, using seatbelt, ROR and hit fixed object on straight and curve segment of roadway, mounted traffic island, intersection-related and accident in April. This study recommends the need to improve road safety campaign, law enforcement, and roadside safety features that potentially reduce level of severity of driver involving in singlevehicle ROR crash.
\end{abstract}

Keywords: Driver injury severity, single-vehicle ROR crash, multinomial logit, Thailand.

ENGINEERING JOURNAL Volume 24 Issue 5

Received 9 December 2019

Accepted 3 August 2019

Published 30 September 2020

Online at https:/ / engj.org/

DOI:10.4186/ej.2020.24.5.207 


\section{Introduction}

According to the report on road safety of World Health Organization (WHO) [1], traffic accident on Highways is becoming worse problem from year to year, the number of fatalities due to traffic accident have increased from 1.25 million (2013) to 1.35 million people (2016), and up to 50 million were injured in just a single year; numerically, almost 3700 victims die on the world road every day. The greatest burden of injury and fatality from road accidents has been occurring in most of the low- and middle-income countries. Being one of the middle-income countries in Southeast Asia, Thailand is currently under the process of development in all sectors including improvement in the transportation sector to be faster, safer, and more comfortable for all road users. Whereas, this expansion has led to an increasing trend of the capacity of the personal vehicles operate on road and accident on the road that caused significant loss of lives and economy. In 2015, the rate of fatalities due to the accident was 36.2 per 100000 and ranked second in the world after Libya, and this trend has decreased to 32.7 in 2018 which is considered to be still significantly high.

Based on seven-years accident record (2011 -2017) obtained from Highway Accident Information Management System (HAIMS) of the Department Of Highway $(\mathrm{DOH})$, Thailand's number of run-off-road (ROR) crash was the leading type of crash among all crash types and caused the highest number of injuries and fatalities on highway and in hospital. ROR crash alone accounted for $52 \%$ out of total accidents (53485 cases) followed by rearend crash at only $26 \%$ (consistent with three-year accident 2014-2016 data used in the previous study [2]). Additionally, 9877 cases happened to be single-vehicle ROR crash which killed 1361 drivers and caused serious injury 1406 drivers out of 9877 drivers. However, there is no previous research study that specifically in-depth identifying risk factors influencing the severity of driver involving in a single-vehicle ROR crash for Thailand Highway yet. Therefore, this research paper aims to fulfill the gap to explore factors contributing to driver injury severity involving in single-vehicle ROR crash for Thailand highway using multinomial logit model. The contribution of this study can provide insight into future traffic safety policies that may potentially reduce driver injury severity involving in a single-vehicle ROR crash on Thailand Highway.

\section{Literature Review}

The analysis of crash severity to identify the significant risk factors has been conducted by many researchers. Yasmin and Eluru [3] reviewed many previous works on their methodological approach and factors that were considered for crash severity analysis and five main characteristics were used in almost every existing research including the driver, roadway and operational design, vehicle, temporal and environmental, and crash characteristic. In traffic safety research, driver characteristics have been considered a significant influence on the crash injury severity [3]. Liu and Ye [4] found that driver-related factors were the major causes of the single-vehicle ROR crash including performance error, sleepiness, driver under influence (DUI), overcompensation, and distraction. The influences of age groups were also found as a potential risk factor that could affect driver injury severity. Drivers younger than 25 years old were less likely to be severely injured in the singlevehicle crash [5-7]; while, older drivers were found to be more associated with fatal ROR crash $[8,9]$. The uses of seatbelt while driving were also found as potential safety equipment that prevents the victim of ROR crash from severe injury [10-13]. In terms of gender, female drivers are likely to get more severely injured in single-vehicle ROR crash [13-15]. Potential risk factors affecting the severity of the ROR crash can also have a relationship with the vehicle types. Schneider, et al. [13]'s study revealed that pickup truck drivers have higher possibility to be severely injured followed by passenger car and semitrailer truck in the ROR crash. The influence of roadway characteristics on driver injury severity was also studied in the existing literature. Peng, et al. [16]'s research study found some factors that positively affect injury of the single-vehicle ROR crashes such as wider shoulder width and wider lateral clearance which increase the opportunity to recovery back to the travel lane and decrease the probability of hitting fixed-object on the side of the road, respectively. Liu and Subramanian [17] also highlighted that road alignment with curve, rural roadway, and highspeed limit road were significantly associated with a high risk of being in the fatal single-vehicle ROR crash. Concerning environmental characteristic, Lee and Mannering [5] found that ROR crash during clear or cloudy and on the wet road was likely to result in a less severe crash than those that had ice or snow on roadway, foggy and raining, or snowing condition. Russo, et al. [18] argued that the injury crash possibly caused by the failure of road geometry that is firmly associated with road comfort, road familiarity, road section, environment, and ability to perceive the curve road ahead.

\section{Methodology and Data}

\subsection{Methodological Approach}

In the accident analysis study, the injury severity outcomes can be treated as the unordered category or natural ordering to analyze the unordered response model and the ordered response model, respectively. Numbers of the researcher also utilized the ordered framework for their accident severity analysis, namely generalized ordered logit [19-21], heteroscedastic ordered logit [22, 23], and ordered probit [24]. However, one of the most commonly used unordered respond framework; multinomial logit, was used to identify the risk factors affecting severity of motorcycle crash [25], injury severity of the road accident in the Erzurum and Kars province of Turkey [26], pedestrian-vehicle crash severity [27], driver 
injury severity in the intersection-related crash [28]. The advantages of the unordered response model over the ordered response model are providing more flexible control over the interior category probability [26] and no need to account for ordinal categorical outcome while the ordered response model occasionally urge unrealistic parameter restriction [29]. Hence, in this study, multinomial logit is adopted for single-vehicle ROR crash driver injury severity analysis for Thailand highway. Following the previous study [30], suppose that $T_{i j}$ is the linear function that determines the severity level $j$ in the accident $i$ and $P_{i j}$ is the probability of a driver $i$ th being of severity $j$ :

$$
\begin{gathered}
T_{i j}=\beta_{j} X_{i j}+\varepsilon_{i j} \\
P_{i j}=\frac{E X P\left[\beta_{j} X_{i j}\right]}{\sum_{j} E X P\left[\beta_{j} X_{i j}\right]}
\end{gathered}
$$

where $\beta_{j}$ is a vector of the coefficients to be estimated for injury severity outcome $j, X_{i j}$ is the vector of explanatory variable and $\varepsilon_{i j}$ is the unobserved random error.

Since multinomial logit requires firm consideration of correlation between the independent variable and dependent variable and possible multicollinearity among the independent variable; thus, the Pearson' chi-square test is estimated to evaluate the relationship between each risk factor and driver injury severity [31].

Odd ratio (OR) of each significant risk factors are used to interpret the estimated results. $O R>1$ indicates an increase of probability and $O R<1$ indicates a decrease of probability of that injury severity with relative to base category injury severity. The formula of OR is given as:

$$
O R=E X P\left(\beta_{j}\right)
$$

\subsection{Data Description}

This research study used the single-vehicle ROR crash data between 2011-2017 that occurred on Thailand highways which originally obtained from HAIMS. All available variables associated with each accident case and driver severity were extracted and categorized into factors namely, driver factors, vehicle factors, roadway factors, crash characteristics factors, and environmental and temporal factors. Only single-vehicle ROR crashes were used; and crashes with incomplete information (due to insufficient details in the police report) were neglected from the study. During this seven-year period, there were 9877 single-vehicles ROR crashes happened. The total extracted risk factors for each case were 40 explanatory variables. Each variable was coded $1=$ "Yes", $0=$ "Otherwise" except GENDER 1 = "Male", 0 = "Female"; R_SURF $1=$ "Concrete pavement", $0=$ "Asphalt pavement"; and EN_SURF 1 = "Road with dry surface", 0 $=$ "Road with wet surface". Table 1 summarizes all the possible risk factors descriptively with each level of driver injury severity. The injury severity outcome of each driver was categorized into three levels of injury (Fatal/Serious/ Minor Injury). The recommended minimum sample size for the multinomial logit model is 2000 observations [31]; therefore, the sample size in this study is acceptable.

\section{Results and Discussions}

Before fitting all risk factors into the multinomial logit model, Chi-square and log-likelihood ratio test was conducted to test independence and association between each risk factor and driver injury severity. Table 2 presents the results of Chi-square and $\log$-likelihood ratio test. The results show that some factors are not statistically significant at 0.05 level, namely AGE_36_45, AGE_46_55, PASS_INFRONT, DEFECT_CAR, DEFECT_CAR, PASSENGER_CAR, PICKUP_INVOLVE, R_COND, R_SURF, VERTICAL, COMMUNITY, DEPRESSED_MEDIAN, EN_STAT, EN_LIGHT, and TIMEGROUP. Consequently, all these independent variables (risk factors) were not included in the final multinomial logit model estimation.

Table 3 presents the multinomial logit estimated results of single-vehicle ROR driver injury severity. The base dependent category is fatal injury (follow the previous research studies of $[26,31])$. There were totally 26 independent variables that have a strong association with driver injury severity based on the results of Table 2 with 9877 observations were used for analysis in the final model. The odd ratio (OR) of each significant variable is used to interpret the predicted probability of the odd that the independent variables are likely to fall into a specific injury categories. The model fitting information is shown in Table 3 with Chi-square $=790.836$ and significantly small $\mathrm{P}$-value $=0.000$, thus the multinomial logit model was fit fairly well. McFadden R2: 0.0508 is relatively small, but has been used in the previous works [32, 33].

The estimated results show that drivers age between 26-35 years old was more likely $(\mathrm{OR}=1.18,95 \% \mathrm{CI}=$ 1.03-1.35) to have minor injury in the accident when compared with the fatal injury. The minor injury severity level for this age group is 1.18 times more likely to occur than fatal injury. In contrast, driver age older than 55 years old was found to be more likely $(\mathrm{OR}=0.750,95 \% \mathrm{CI}=$ $0.57-0.98)$ to fall into fatal injury rather than severe injury. In this case, older drivers are 1.33 times more likely to die in the accident relative to severe injury. To our best understanding, this is because young drivers have better health, physically body condition, and perception reaction to the situation than the older driver (age is strongly correlated with human physical characteristics [34]). In addition, this result is in line with previous research [35]. Similarly, the negative coefficient of variable GENDER indicates that male drivers are likely to have higher risk of falling into fatal accident than females with relative to minor injury $(\mathrm{OR}=0.763,95 \% \mathrm{CI}=0.62-092)$. This res- 
Table 1. Descriptive statistic of risk factors.

\begin{tabular}{|c|c|c|c|c|c|c|}
\hline \multirow{2}{*}{$\begin{array}{l}\text { Variable Name } \\
\text { Driver factors }\end{array}$} & \multirow[t]{2}{*}{ Variable Description } & \multirow[t]{2}{*}{ Minor } & \multirow[t]{2}{*}{ Severe } & \multirow[t]{2}{*}{ Fatal } & \multicolumn{2}{|c|}{ Total } \\
\hline & & & & & & \\
\hline AGE_26_35 & Age 26-35 years old & 2446 & 457 & 414 & 3317 & $33.6 \%$ \\
\hline AGE_36_45 & Age $36-45$ years old & 1719 & 358 & 351 & 2428 & $24.6 \%$ \\
\hline AGE_46_55 & Age $46-55$ years old & 1115 & 215 & 232 & 1562 & $15.8 \%$ \\
\hline AGE_56_UP & Age $>55$-year-old & 581 & 106 & 137 & 824 & $8.3 \%$ \\
\hline \multirow{2}{*}{ GENDER } & Female driver & 931 & 171 & 144 & 1246 & $12.6 \%$ \\
\hline & Male driver & 6179 & 1235 & 1217 & 8631 & $87.4 \%$ \\
\hline SAF_EQ & Used Seatbelt & 2919 & 544 & 459 & 3922 & $39.7 \%$ \\
\hline ALCOHOL & Under alcohol influence & 94 & 32 & 46 & 172 & $1.7 \%$ \\
\hline EXEED_SPEED & Exceed speed limit & 5587 & 1111 & 981 & 7679 & $77.7 \%$ \\
\hline FALL_ASLEEP & Fall asleep & 801 & 168 & 222 & 1191 & $12.1 \%$ \\
\hline PASS_INFRONT & Something passes in front & 172 & 27 & 23 & 222 & $2.2 \%$ \\
\hline \multicolumn{7}{|l|}{ Vehicle factors } \\
\hline DEFECT_CAR & Defective car device & 249 & 42 & 49 & 340 & $3.4 \%$ \\
\hline PASSENGER_CAR & Passenger car & 2474 & 519 & 455 & 3448 & $34.9 \%$ \\
\hline PICKUP_INVOLVE & Pickup truck & 3170 & 601 & 571 & 4342 & $44.0 \%$ \\
\hline TRUCK_INVOLVE & Heavy truck/trailer & 1044 & 164 & 195 & 1403 & $14.2 \%$ \\
\hline \multicolumn{7}{|l|}{ Crash characteristics factors } \\
\hline OFF_LEFT_STRAIGHT & ROR to left on straight & 439 & 166 & 276 & 881 & $8.9 \%$ \\
\hline OFF_RIGHT_STRAIGHT & ROR to right on straight & 251 & 80 & 167 & 498 & $5.0 \%$ \\
\hline LEFT_FIXED_STRAIGHT & ROR to left/hit object & 1328 & 221 & 143 & 1692 & $17.1 \%$ \\
\hline RIGHT_FIXED_STRAIGHT & ROR to right/hit object & 1172 & 220 & 135 & 1527 & $15.5 \%$ \\
\hline ACROSS_MEDIAN & ROR and across median & 131 & 36 & 44 & 211 & $2.1 \%$ \\
\hline OFF_LEFT_CUVE & ROR on left bend & 197 & 38 & 89 & 324 & $3.3 \%$ \\
\hline OFF_RIGHT_CUVE & ROR on right bend & 167 & 47 & 72 & 286 & $2.9 \%$ \\
\hline LEFT_FIXED_CURVE & ROR on left bend/hit object & 690 & 113 & 107 & 910 & $9.2 \%$ \\
\hline RIGHT_FIXED_CURVE & ROR on right bend/hit object & 786 & 120 & 118 & 1024 & $10.4 \%$ \\
\hline MOUNT_ISLAND & Mounted traffic island & 1808 & 335 & 166 & 2309 & $23.4 \%$ \\
\hline R_COND & Occurred in construction area & 155 & 41 & 37 & 233 & $2.4 \%$ \\
\hline \multicolumn{7}{|l|}{ Road factors } \\
\hline N_LANE & Happened on 2 lanes road & 1873 & 371 & 449 & 2693 & $27.3 \%$ \\
\hline \multirow{2}{*}{ R_SURF } & Concrete pavement road & 506 & 120 & 102 & 728 & $7.4 \%$ \\
\hline & Asphalt pavement road & 6604 & 1286 & 1259 & 9149 & $92.6 \%$ \\
\hline VERTICAL & Road on grade area & 716 & 150 & 152 & 1018 & $10.3 \%$ \\
\hline INTERSECTION & Intersection area & 524 & 88 & 58 & 670 & $6.8 \%$ \\
\hline U_TURN & U-turn area & 681 & 119 & 63 & 863 & $8.7 \%$ \\
\hline COMMUNITY & Community area & 63 & 17 & 11 & 91 & $0.9 \%$ \\
\hline NO_MEDIAN & Without median & 2005 & 401 & 485 & 2891 & $29.3 \%$ \\
\hline RAISED_MEDIAN & Raised median & 1937 & 367 & 261 & 2565 & $26.0 \%$ \\
\hline DEPRES_MEDIAN & Depressed median & 2470 & 517 & 502 & 3489 & $35.3 \%$ \\
\hline \multicolumn{7}{|c|}{ Environmental and temporal factors } \\
\hline \multirow{2}{*}{ EN_SURF } & Dry surface road & 5651 & 1149 & 1121 & 7921 & $80.2 \%$ \\
\hline & Wet surface road & 1459 & 257 & 240 & 1956 & $19.8 \%$ \\
\hline EN_STAT & Dirt/dusty road & 23 & 5 & 6 & 34 & $0.3 \%$ \\
\hline EN_WEATHER & Raining, dust, foggy & 1553 & 272 & 258 & 2083 & $21.1 \%$ \\
\hline
\end{tabular}


Table 1. Descriptive statistic of risk factors (cont.)

\begin{tabular}{lllllll}
\hline EN_LIGHT & Nighttime & 3328 & 678 & 652 & 4658 & $47.2 \%$ \\
TIMEGROUP & 6 pm-midnight & 1236 & 261 & 244 & 1741 & $17.6 \%$ \\
APRIL_ACCIDENT & Happened in April & 752 & 213 & 204 & 1169 & $11.8 \%$ \\
\hline
\end{tabular}

Table 2. Chi-square test and log-likelihood ratio test of association between risk factors and driver injury severity.

\begin{tabular}{|c|c|c|c|}
\hline Variable & Chi-square test (P-value) & Log Likelihood test (P-value) & df \\
\hline AGE_26_35 & $8.9831(0.010)$ & $9.0807(0.010)$ & 2 \\
\hline AGE_36_45 & - & - & - \\
\hline AGE_46_55 & - & - & - \\
\hline AGE_56_UP & $6.7462(0.034)$ & $6.4841(0.039)$ & 2 \\
\hline GENDER & $6.8533(0.032)$ & $7.097(0.028)$ & 2 \\
\hline SAF_EQ & $26.343(<0.001)$ & $26.737(<0.001)$ & 2 \\
\hline ALCOHOL & $31.007(<0.001)$ & $26.891(<0.001)$ & 2 \\
\hline EXCEED_SPEED & $29.48(<0.001)$ & $28.134(<0.001)$ & 2 \\
\hline FALL_ASLEEP & $27.444(<0.001)$ & $25.523(<0.001)$ & 2 \\
\hline PASS_INFRONT & - & - & - \\
\hline DEFECT_CAR & - & - & - \\
\hline PASSENGEER_CAR & - & - & - \\
\hline PICKUP_INVO-_LVE & - & - & - \\
\hline TRUCK_INVOLVE & $8.8001(0.012)$ & $9.1965(0.01)$ & 2 \\
\hline OFF_LEFT_STRAIGHT & $296.55(<0.001)$ & $250.75(<0.001)$ & 2 \\
\hline OFF_RIGHT_STRAIGHT & $183.69(<0.001)$ & $146.91(<0.001)$ & 2 \\
\hline LEFT_FIXED_STRAIGHT & $56.027(<0.001)$ & $61.249(<0.001)$ & 2 \\
\hline RIGHT_FIXED_STRAIGHT & $37.709(<0.001)$ & $41.477(<0.001)$ & 2 \\
\hline ACROSS_MEDIAN & $11.975(0.003)$ & $10.993(0.004)$ & 2 \\
\hline OFF_LEFT_CUVE & $52.858(<0.001)$ & $43.308(<0.001)$ & 2 \\
\hline OFF_RIGHT_CUVE & $36.316(<0.001)$ & $31.438(<0.001)$ & 2 \\
\hline LEFT_FIXED_CURVE & $7.350(0.025)$ & $7.554(0.023)$ & 2 \\
\hline RIGHT'_FIXED_CURVE & $12.916(0.002)$ & $13.362(0.001)$ & 2 \\
\hline MOUNT_ISLAND & $111.84(<0.001)$ & $126.07(<0.001)$ & 2 \\
\hline R_COND & - & - & - \\
\hline N_LANE & $26.09(<0.001)$ & $25.245(<0.001)$ & 2 \\
\hline R_SURF & - & - & - \\
\hline VERTICAL & - & - & - \\
\hline INTERSECTION & $18.168(<0.001)$ & $20.039(<0.001)$ & 2 \\
\hline U_TURN & $35.243(<0.001)$ & $40.527(<0.001)$ & 2 \\
\hline COMMUNITY & - & - & - \\
\hline NO_MEDIAN & $30.954(<0.001)$ & $29.995((<0.001)$ & 2 \\
\hline RAISED_MEDIAN & $38.675(<0.001)$ & $40.801(<0.001)$ & 2 \\
\hline DEPRESSED_MEDIAN & - & - & - \\
\hline EN_SURF & $8.392(0.01)$ & $8.5309(0.01)$ & 2 \\
\hline EN_STAT & - & - & - \\
\hline EN_WEATHER & $8.7118(0.01)$ & $8.8428(0.01)$ & 2 \\
\hline EN_LIGHT & - & - & - \\
\hline TIMEGROUP & - & - & - \\
\hline APRIL_ACCIDENT & $38.565(<0.001)$ & $36.987(<0.001)$ & 2 \\
\hline
\end{tabular}


Table 3. Multinomial Logit model of Thailand ROR crash severities.

\begin{tabular}{|c|c|c|c|c|}
\hline \multirow[t]{2}{*}{ Variable } & \multicolumn{2}{|c|}{ Minor } & \multicolumn{2}{|c|}{ Severe } \\
\hline & Coefficient & OR $(95 \% \mathrm{CI})$ & Coefficient & OR $(95 \% \mathrm{CI})$ \\
\hline Constant & $1.216(0.223) * *$ & & $-0.495(0.296) *$ & \\
\hline AGE_26_35 & $0.165(0.068) * *$ & $1.180(1.03-1.35)$ & - & - \\
\hline AGE_56_UP & - & - & $-0.288(0.141) * *$ & $0.750(0.57-0.98)$ \\
\hline GENDER & $-0.271(0.100) * * *$ & $0.763(0.62-0.92)$ & - & - \\
\hline SAF_EQ & $0.374(0.065) * * *$ & $1.453(1.27-1.65)$ & $0.269(0.081) * * *$ & $1.308(1.11-1.53)$ \\
\hline ALCOHOL & $-0.858(0.202) * * *$ & $0.424(0.28-0.63)$ & - & - \\
\hline EXEED_SPEED & - & - & - & - \\
\hline FALL_ASLEEP & $-0.323(0.126)^{* * *}$ & $0.724(0.56-0.92)$ & - & - \\
\hline TUCK_INVOLVE & - & - & - & - \\
\hline OFF_LEFT_STRAIGHT & $-0.609(0.192) * * *$ & $0.544(0.37-0.79)$ & - & - \\
\hline OFF_RIGHT_STRAIGHT & $-0.682(0.204) * * *$ & $0.506(0.33-0.75)$ & - & - \\
\hline LEFT_FIXED_STRAIGHT & $1.117(0.197) * * *$ & $3.056(2.09-4.49)$ & $0.833(0.264) * * *$ & $2.301(1.37-3.84)$ \\
\hline RIGHT_FIXED_STRAIGH & $1.016(0.199) * * *$ & $2.761(1.87-4.07)$ & $0.850(0.264) * * *$ & $2.304(1.39-3.92)$ \\
\hline ACROSS_MEDIAN & - & - & - & - \\
\hline OFF_LEFT_CUVE & - & - & - & - \\
\hline OFF_RIGHT_CUVE & - & - & - & - \\
\hline LEFT_FIXED_CURVE & $0.693(0.204) * * *$ & $2.000(1.34-2.98)$ & - & - \\
\hline RIGHT_FIXED_CURVE & $0.719(0.202) * * *$ & $2.052(1.38-3.04)$ & - & - \\
\hline MOUNT_ISLAND & $1.148(0.196) * * *$ & $3.153(2.14-4.63)$ & $0.998(0.260) * * *$ & $2.714(1.63-4.52)$ \\
\hline N_LANE & - & - & - & - \\
\hline INTERSECTION & $0.316(0.147) * *$ & $1.372(1.02-1.83)$ & - & - \\
\hline U_TURN & - & - & - & - \\
\hline NO_MEDIAN & - & - & - & - \\
\hline RAISED_MEDIAN & - & - & - & - \\
\hline EN_SURF & - & - & - & - \\
\hline EN_WEATHER & - & - & - & - \\
\hline APRIL_ACCIDENT & - & - & $0.245(0.110) * *$ & $1.278(1.03-1.58)$ \\
\hline \multicolumn{5}{|c|}{$\begin{array}{l}\text { Fatal injury is the base category; } \\
(-) \text { not significant; }(*) \mathrm{p} \text {-value }<0.1 ;(* *) \mathrm{p} \text {-value }<0.05 ;(* * *) \mathrm{p} \text {-value }<0.000 \\
\text { Number of observations }=9877 ; \\
\text { Log-Likelihood: }-7380.1 ; \\
\text { McFadden R2: } 0.050854 ; \\
\text { Likelihood ratio test: } \chi^{2}=790.84 ; \mathrm{df}=52(\mathrm{p} \text {-value }<0.000)\end{array}$} \\
\hline
\end{tabular}


-ult is consistent with the finding of past studies [36-38]. However, this finding contrasts with some of the previous works as presented in the current literature review. A reasonable explanation is the differences in driving behavior (driving speed, decision making relative to possible risk, uses of alcohol/drug, or ability to resist drowsiness) of males versus females in different regions.

The driver who used seatbelt while driving is found to significantly reduce the rate of being in fatal crash relative to both minor and severe injury with $(\mathrm{OR}=1.43,95 \% \mathrm{CI}$ $=1.27-1.65$ and $\mathrm{OR}=1.308,95 \%, \mathrm{CI}=1.11-1.53$, respectively) in case of ROR crash happened, which is logical finding, and consistent with the result of the previous work $[13,39]$.

The results for drivers under influence of alcohol are almost 2.36 times higher possibility $(\mathrm{OR}=0.424,95 \% \mathrm{CI}$ $=0.28-0.63)$ to die in the accident relative to the minor injury category which is reasonable finding and consensus with the past studies $[17,40]$. This might be a significantly important finding, since during long holiday season such as New Years and Songkran, numbers of the accident increase dramatically and kill significant numbers of citizen due to drunk driving which Thailand authority has been trying to tackle every year. Drowsiness also have potential to influence injury severity. Accidents caused by driver falling asleep have higher possibility $(\mathrm{OR}=0.724$ $95 \% \mathrm{CI}=0.56-0.92)$ to die rather than get minor injury, probably because of drowsiness put crash in the position where the strong impact is produced due to unpreparedness for the accident.

With regard to crash characteristics, the results show that the single-vehicle ROR crash on straight to both left or right are likely $(\mathrm{OR}=0.544,95 \% \mathrm{CI}=0.37-0.79$ and $\mathrm{OR}=0.506,95 \% \mathrm{CI}=0.33-0.75$, respectively) to fall into fatal injury than minor injury. However, the estimated result indicates that the minor injury is around 3 and 2.7 times $(\mathrm{OR}=3.056,95 \% \mathrm{CI}=2.09-4.49$ and $\mathrm{OR}$ $=2.76195 \% \mathrm{CI}=1.87-4.07)$ are more likely to occur than fatality for ROR to the left or right on straight and hit fixed object respectively; additionally, severe injury accident is also more likely $(\mathrm{OR}=2.301 \mathrm{CI}=1.37-3.84$ and $\mathrm{OR}=2.304, \mathrm{CI}=1.39-3.92$ respectively) to occur than fatal accident. For single-vehicle ROR on curve to left or right and hit fixed object is likely to have minor and severe injury 2 times higher $(\mathrm{OR}=2.00095 \% \mathrm{CI}=1.34$ -2.98 and $\mathrm{OR}=2.052,95 \% \mathrm{CI}=1.38-3.04$ respectively) than fatality. This result is consensus with the finding of previous studies $[5,37]$. However, Dissanayake and Roy [8] argued that crash with fixed object are likely to increase the probability of more severe injury. The possible explanation was stated in work of Lee and Mannering [5] that the severity of ROR accident can be complicated considering association with roadside features such as other fixed objects, guardrail, traffic sign poles and other purpose sign pole along the roadway in addition to the difference of driver characteristics such as speed, driver condition, or awareness along the roadway sections. additionally, driver behavior in Thailand tends to drive using higher speed $(77.7 \%$ of total single-vehicle ROR crashes were caused by exceeding the speed limit), thus in case of vehicle getting into ROR crash, the driver tends to overcorrect and transfer into rollover crash; in this manner, it increases chances of more severe crashes to the driver rather than ROR and hit the fixed object. Considering the accidents on curve sections, the current results make sense because the ROR on curve injury severity could reduce significantly by safety barrier (guardrail) on the side of curve road as object to prevent the vehicle from running out of the road and rollover crashes, and functionally can absorb the energy from the crash to reduce the crash impact as well as crash severity.

The driver who mounted traffic island is less likely $(\mathrm{OR}=3.153,95 \% \mathrm{CI}=2.14-4.63$ minor injury, $\mathrm{OR}=$ $2.714,95 \% \mathrm{CI}=1.63-4.52$ severe injury) to die in the accident. This is because of traffic island's function is the traffic calming device that force driver to reduce the speed that might lower the crash impact as well as crash severity. Similarly, within the intersection areas, ROR crash type drivers are less likely $(\mathrm{OR}=1.372,95 \% \mathrm{CI}=1.02-1.83)$ to die in the accident relative to minor injury level. Within intersection areas, driver may be more careful when vehicle approach intersection and likely to drive at a slower speed. Even though in case of ROR accident due to obstacle ahead, it may not increase the driver severity level.

April is the period that Thailand experiences the highest accident frequency, drivers are likely $(\mathrm{OR}=1.278$, $95 \% \mathrm{CI}=1.03-1.58$ to fall into severe injury rather than fatal injury in the accident and not significant between fatal and minor injury. However, the fatality frequency during this period is $204(17.45 \%)$, and severely injured is 213 $(18.22 \%)$ out of 1169 victims were still considerably high when compared to numbers of victims throughout the year.

\section{Conclusions and Recommendations}

In Thailand, the single-vehicle ROR accident accounted for $18 \%$ of the total crashes and claimed a significant loss of life and disability. Therefore, the objective of this study is to identify potential risk factors affecting the driver injury severity of the single-vehicle ROR crash for Thailand highway. Multinomial logit model was used to estimate 9877 accident records and 40 risk factors were included under five factors namely, driver, vehicle, roadway, crash characteristic, and environmental and temporal factors.

The estimated results show that old drivers, male drivers, drivers under influence (alcohol), drowsiness, ROR to left/right on straight roadway increase the probability of fatal crash, while other factors are found to mitigate severity such as driver age between 26-35 years old, use of seatbelt, ROR and hit fixed object on straight and curve segment of roadway, mounted traffic island, intersection related and April accident. With regard to the results of the current study, Thailand road safety relatedauthorities such as Department of Highway and royal police department are recommended to emphasize their 
future effort on improving education campaigns on road safety specifically for old and male drivers with intention to change their risky driving attitude (reckless driving, driving too fast, drowsy driving etc.), increase the awareness and knowledge on the causes, location, and mechanism of the crash. Secondly, enforce the law on drunk driving, seatbelt usage, overspeed driving, by increasing more traffic checkpoint to reduce number of traffic safety law violations. Lastly, it is essential to provide and monitor roadside safety features such as guardrail to protect the vehicle from high impact crash with trees [41], particularly ROR black spot and curve roads that can be identified by using potential saving in accident costs proposed by past study [42] with intention to promote safety improvement measures that could be implemented with the greatest economical effectiveness.

The contributions of this study are limited in terms of prediction accuracy due to possible under-reporting data of the police recorded accident reports that may lead to biased estimated results. Secondly, other insufficient information of driver behaviours (such as overcorrection, health condition, driver skill, and ejection), vehicles (vehicle age, size, weight), road properties (shoulder type, roadside treatment, sides lope, curve radius), and crash characteristics (detail of fixed object, sequences of crash). In spite of these shortcomings, this study is the first attempt that provides an inside statistical method to reveal the risk factors that influencing driver injury severity of single-vehicle ROR crash for Thailand highway. Future research should focus more on the validity and reliability of the police crash reports and investigate more contributed risk factors in order to increase the prediction accuracy of the model.

\section{References}

[1] WHO, "Global status report on road safety 2018," World Health Organization, 2018.

[2] T. Champahom, S. Jomnonkwao, D. Watthanaklang, A. Karoonsoontawong, V. Chatpattananan, and V. Ratanavaraha, "Applying hierarchical logistic models to compare urban and rural roadway modeling of severity of rear-end vehicular crashes," Accid Anal \& Prev, vol. 141, p. 105537, 2020.

[3] S. Yasmin and N. Eluru, "Evaluating alternate discrete outcome frameworks for modeling crash injury severity," Accid Anal \& Prev, vol. 59, pp. 506521, 2013.

[4] C. Liu and T. J. Ye, "Run-off-road crashes: An onscene perspective,” NHTSA, No. HS-811 500, 2011.

[5] J. Lee and F. Mannering, "Impact of roadside features on the frequency and severity of run-offroadway accidents: an empirical analysis," Accid Anal \& Prev, vol. 34, no. 2, pp. 149-161, 2002.

[6] P. Savolainen and F. Mannering, "Probabilistic models of motorcyclists' injury severities in singleand multi-vehicle crashes," Accid Anal \& Prev, vol. 39, no. 5, pp. 955-963, 2007.
[7] M. S. Shaheed and K. Gkritza, "A latent class analysis of single-vehicle motorcycle crash severity outcomes," Anal Meth Accid Res, vol. 2, pp. 30-38, 2014.

[8] S. Dissanayake and U. Roy, "Crash severity analysis of single vehicle run-off-road crashes," J of Trans Techn, vol. 4, no. 01, p. 1, 2014.

[9] S. Das and X. Sun, "Association knowledge for fatal run-off-road crashes by Multiple Correspondence Analysis," IATSS Res, vol. 39, no. 2, pp. 146-155, 2016.

[10] N. S. S. Al-Bdairi and S. Hernandez, "An empirical analysis of run-off-road injury severity crashes involving large trucks," Accid Anal \& Prev, vol. 102, pp. 93-100, 2017.

[11] M. Islam and S. Hernandez, "Large truck-involved crashes: exploratory injury severity analysis," J of Trans Eng, vol. 139, no. 6, pp. 596-604, 2013.

[12] Y. Peng and L. N. Boyle, "Commercial driver factors in run-off-road crashes," Trans Res Rec, vol. 2281, no. 1, pp. 128-132, 2012.

[13] W. H. Schneider, P. T. Savolainen, and K. Zimmerman, "Driver injury severity resulting from single-vehicle crashes along horizontal curves on rural two-lane highways," Trans Res Rec, vol. 2102, no. 1, pp. 85-92, 2009.

[14] C. Roque, F. Moura, and J. L. Cardoso, "Detecting unforgiving roadside contributors through the severity analysis of ran-off-road crashes," Accid Anal \& Prev, vol. 80, pp. 262-273, 2015.

[15] Q. Wu, F. Chen, G. Zhang, X. C. Liu, H. Wang, and S. M. Bogus, "Mixed logit model-based driver injury severity investigations in single-and multi-vehicle crashes on rural two-lane highways," Accid Anal \& Prev, vol. 72, pp. 105-115, 2014.

[16] Y. Peng, S. R. Geedipally, and D. Lord, "Effect of roadside features on single-vehicle roadway departure crashes on rural two-lane roads," Trans Res Rec, vol. 2309, no. 1, pp. 21-29, 2012.

[17] C. Liu and R. Subramanian, "Factors related to fatal single-vehicle run-off-road crashes," NHTSA, No. HS-811 232, 2009.

[18] F. Russo, R. Di Pace, G. Dell'Acqua, and S. De Luca, "Estimating an Injury Crash Rate Prediction Model based on severity levels evaluation: the case study of single-vehicle run-off-road crashes on rural context," Trans Res Proc, vol. 27, pp. 1088-1096, 2017.

[19] T. Abegaz, Y. Berhane, A. Worku, A. Assrat, and A. Assefa, "Effects of excessive speeding and falling asleep while driving on crash injury severity in Ethiopia: a generalized ordered logit model analysis," Accid Anal \& Prev, vol. 71, pp. 15-21, 2014.

[20] S. Kaplan and C. G. Prato, "Risk factors associated with bus accident severity in the United States: A generalized ordered logit model," J of Saf Res, vol. 43, no. 3, pp. 171-180, 2012.

[21] S. Yasmin, N. Eluru, C. R. Bhat, and R. Tay, "A latent segmentation based generalized ordered logit model to examine factors influencing driver injury 
severity," Anal Meth in Accid Res, vol. 1, pp. 23-38, 2014.

[22] X. Wang and K. M. Kockelman, "Use of heteroscedastic ordered logit model to study severity of occupant injury: distinguishing effects of vehicle weight and type," Trans Res Rec, vol. 1908, no. 1, pp. 195-204, 2005.

[23] X. Wang and K. M. Kockelman, "Occupant injury severity using a heteroscedastic ordered logit model: distinguishing the effects of vehicle weight and type," Trans Res Rec, vol. 1908, pp. 195-204, 2005.

[24] M. Abdel-Aty, "Analysis of driver injury severity levels at multiple locations using ordered probit models," J of Saf Res, vol. 34, no. 5, pp. 597-603, 2003.

[25] D. Chimba and T. Sando, "Multinomial probability assessment of motorcycle injury severities," Advan in Trans Stud, vol. 21, pp. 73-80, 2010.

[26] A. K. Celik and E. Oktay, "A multinomial logit analysis of risk factors influencing road traffic injury severities in the Erzurum and Kars Provinces of Turkey," Accid Anal \& Prev, vol. 72, pp. 66-77, 2014.

[27] R. Tay, J. Choi, L. Kattan, and A. Khan, "A multinomial logit model of pedestrian-vehicle crash severity," Inter J of Sus Trans, vol. 5, no. 4, pp. 233249, 2011.

[28] Q. Wu, G. Zhang, Y. Ci, L. Wu, R. A. Tarefder, and A. D. Alcántara, "Exploratory multinomial logit model-based driver injury severity analyses for teenage and adult drivers in intersection-related crashes," Traf Inj Prev, vol. 17, no. 4, pp. 413-422, 2016.

[29] P. T. Savolainen, F. L. Mannering, D. Lord, and M. A. Quddus, "The statistical analysis of highway crash-injury severities: a review and assessment of methodological alternatives," Accid Anal \& Prev, vol. 43, no. 5, pp. 1666-1676, 2011.

[30] S. P. Washington, M. G. Karlaftis, and F. Mannering, Statistical and Econometric Methods for Transportation Data Analysis. Chapman and Hall/CRC, 2010.

[31] F. Ye and D. Lord, "Comparing three commonly used crash severity models on sample size requirements: multinomial logit, ordered probit and mixed logit models," Anal Meth in Accid Res, vol. 1, pp. 72-85, 2014.

[32] V. Ratanavaraha and S. Suangka, "Impacts of accident severity factors and loss values of crashes on expressways in Thailand," IATSS Res, vol. 37, no. 2, pp. 130-136, 2014.

[33] A. J. Khattak, M. D. Pawlovich, R. R. Souleyrette, and S. L. Hallmark, "Factors related to more severe older driver traffic crash injuries," J of Trans Eng, vol. 128, no. 3, pp. 243-249, 2002.

[34] F. L. Mannering, V. Shankar, and C. R. Bhat, "Unobserved heterogeneity and the statistical analysis of highway accident data," Anal Meth in Accid Res, vol. 11, pp. 1-16, 2016.

[35] Y. Xie, K. Zhao, and N. Huynh, "Analysis of driver injury severity in rural single-vehicle crashes," Accid Anal \& Prev, vol. 47, pp. 36-44, 2012.

[36] H.-L. Chang and T.-H. Yeh, "Risk factors to driver fatalities in single-vehicle crashes: Comparisons between non-motorcycle drivers and motorcyclists," J of Trans Eng, vol. 132, no. 3, pp. 227-236, 2006.

[37] D. Eustace, O. E. Almutairi, and P. W. Hovey, "Modeling factors contributing to injury and fatality of run-off-road crashes in Ohio," Advan in Trans Stud, Section B, vol. 40, 2016.

[38] M. Shawky, H. M. Hassan, A. M. Garib, and H. A. Al-Harthei, "Examining the factors affecting the severity of run-off-road crashes in Abu Dhabi," Can J of Civ Eng, vol. 43, no. 2, pp. 132-138, 2015.

[39] D. M. Neyens and L. N. Boyle, "The influence of driver distraction on the severity of injuries sustained by teenage drivers and their passengers," Accid Anal \& Prev, vol. 40, no. 1, pp. 254-259, 2008.

[40] G. Li, P. M. Keyl, G. S. Smith, and S. P. Baker, "Alcohol and injury severity: Reappraisal of the continuing controversy," J of Trau and Acute Care Sur, vol. 42, no. 3, pp. 562-569, 1997.

[41] O. Somchainuck, P. Taneerananon, and S. Jaritngam, "An in-depth investigation of roadside crashes on Thai National Highways," Eng J, vol. 17, no. 2, pp. 63-74, 2013.

[42] H. H. Nguyen, P. Taneerananon, and P. Luathep, "Approach to identifying black spots based on potential saving in accident costs," Eng J, vol. 20, no. 2, pp. 109-122, 2016. 


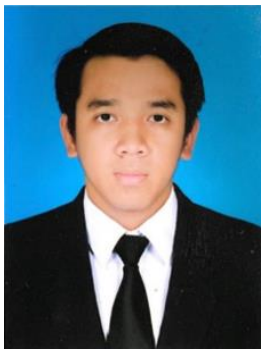

Chamroeun Se received the B.E. (2016), degrees in Civil Engineering from Paragon International University (formerly Zaman University). He is currently a Ph.D student from Suranaree University of Technology (SUT) and has current interest in accident analysis research.

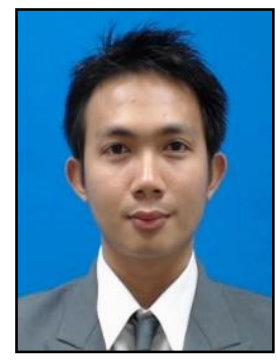

Thanapong Champahom received the B.E. (2015), degrees in Transportation Engineering and Logistics engineering from Suranaree University of Technology (SUT). He is currently a PostDoctoral researcher at SUT and interested in rear-end crash analysis.

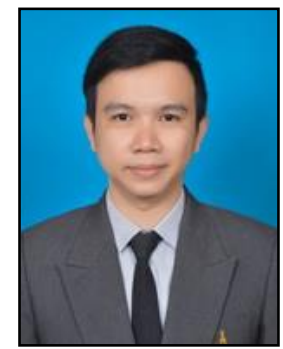

Sajjakaj Jomnonkwao received B.E. (2006), M.E. (2009) and D.E. (2015) degrees in Transportation Engineering and Civil Engineering, He is a Asst. prof., School of Transportation engineering, Suranaree University of Technology. His current interests include public transport (bus, rail, air transportation) and safety

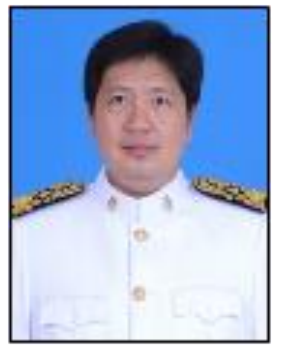

Vatanavongs Ratanavaraha received B.E. (1992), M.E. (1995) and D.E. (1999) degrees in Transportation Engineering and Civil Engineering, from Vanderbilt University. He is a professor of School of Transportation engineering, Suranaree University of Technology. His current interests include public transport and safety research. 